\title{
ANÁLISE E AVALIAÇÃO DA DISTRIBUIÇÃO GEOGRÁFICA DA INFRAESTRUTURA TURÍSTICA NO SÍTIO HISTÓRICO DE PIRENÓPOLIS (GO): SUBSÍDIOS AO PLANEJAMENTO TURÍSTICO ${ }^{1}$
}

\author{
ANALYSIS AND EVALUATION OF THE GEOGRAPHIC DISTRIBUTION \\ OF THE TOURIST INFRASTRUCTURE IN THE HISTORICAL SITE \\ OF PIRENÓPOLIS (GO): SUBSIDIES TO THE TOURIST PLANNING
}

\section{ANÁLISIS Y EVALUACIÓN DE LA DISTRIBUCIÓN GEOGRÁFICA DE LA INFRAESTRUCTURA TURÍSTICA EN LO SITIO HISTÓRICO DE PIRENÓPOLIS (GO): SUBSIDIOS AL PLANEAMIENTO TURÍSTICO}

\author{
Rangel Gomes Godinho - Universidade Federal de Goiás - Goiânia - Goiás - Brasil \\ rangelgodinho@yahoo.com \\ Ivanilton José de Oliveira - Universidade Federal de Goiás - Goiânia - Goiás - Brasil \\ ivanilton.oliveira@gmail.com.br
}

\begin{abstract}
Resumo
A análise e avaliação da distribuição da infraestrutura turística é um importante elemento para compreender como, a partir de objetos técnicos, o turismo produz o espaço geográfico. No caso da cidade goiana de Pirenópolis, os elementos do patrimônio histórico-arquitetônico e do patrimônio natural compõem a oferta turística, que necessita de um conjunto de infraestruturas que subsidiem o uso turístico e potencializem o desenvolvimento dessa atividade. 0 presente trabalho realiza a análise e a avaliação da distribuição da infraestrutura turística no polígono tombado de Pirenópolis, cotejando-a com a localização dos atrativos turísticos, no intuito de compreender sua contribuição para o desenvolvimento do turismo. Com este objetivo, foram realizados diversos levantamentos de campo para identificação e registro da infraestrutura turística e dos atrativos turísticos da área urbana. Esse inventário embasou a construção dos mapas dos atrativos turísticos e da infraestrutura turística, para realização do estudo e, assim, subsidiar as análises e discussões dos resultados. Pode-se concluir que a distribuição geográfica da infraestrutura turística na área tombada obedece a padrões, segundo as diversas tipologias listadas, que não favorecem a visitação e fruição do patrimônio cultural, pois se distribuem aleatoriamente por todo o polígono.
\end{abstract}

Palavras-chave: turismo, cartografia do turismo, patrimônio cultural, infraestrutura turística, Pirenópolis.

\section{Abstract}

The analysis and evaluation of the distribution of tourist infrastructure is an important element to understand how tourism from technical objects produces the geographical space. In Pirenópolis (G0), the elements of historical- architectural heritage and natural heritage make up the tourist offer, that need a set of infrastructure to subsidize tourism and boosting the development of this activity. This study intends analyze and evaluate the distribution of tourist infrastructure at the historical site of Pirenópolis (G0), comparing it with the location of tourist attractions in order to understand its contribution to the development of tourism. For this, diverse surveys of field for identification and register tourist of the infrastructure and tourist attractive at the urban area were carried through, based in this inventory were the constructed the map of tourist attractive and of the tourist infrastructure, for comparing e, thus, to subsidize the analyses and quarrels of the results. It can be concluded that the geographical distribution of tourist infrastructure in the area felled obeys standards by the various types listed, which do not favor the visitation and enjoyment of cultural heritage, as randomly distributed across the polygon.

Key words: tourism, cartography of the tourism, cultural heritage, tourist infrastructure, Pirenópolis. 
Resumen

El análisis y la evaluación de la distribución de la infraestructura turística es un elemento importante para comprender cómo produz el turismo, por los objetos técnicos, el espacio geográfico. En Pirenópolis (G0), los elementos del patrimonio histórico-arquitectónico y natural conforman la oferta turística, necesitan un conjunto de infraestructuras para subsidiar el turismo y potenciar el desarrollo de esta actividad. Por lo tanto, este estudio tiene como objetivo analizar y evaluar la distribución de la infraestructura turística en lo sitio historico de Pirenópolis (G0), comparándolo con la ubicación de las atracciones turísticas a fin de comprender su contribución al desarrollo del turismo. Para esto, exámenes diversos del campo para la identificación y el registro de la infraestructura turística y atractivos turisticos de la área urbana, ese inventario basaron la construcción de los mapas de los atractivos turísticos y de la infraestructura turística, para la realización de su comparación e, así, subvencionar los análisis y discuciones de los resultados. Se puede concluir que la distribución geográfica de la infraestructura turística en el sitio histórico obedece estándares según los distintos tipos enumerados, los cuáles no favorezcan la visitation y el disfrute del patrimonio cultural, porque se distribuyen aleatoriamente para todo el polígono.

Palabras clave: turismo, cartografía del turismo, patrimonio cultural, infraestructura turística, Pirenópolis.

\section{Introdução}

Localizado no estado de Goiás, mais precisamente na microrregião Entorno de Brasília (leste goiano), o município de Pirenópolis, conforme pode ser observado na Figura 1, apresenta um posicionamento geográfico estratégico, por estar próximo dos dois grandes centros urbanos mais dinâmicos de Goiás - Goiânia e Anápolis - e da capital federal, Brasília, que contribuem para a demanda turística do município.

Em Pirenópolis, como afirma Cruz (1998), o turismo, como prática social e atividade econômica que se apropria de elementos do espaço geográfico, tornando-os produtos para o consumo turístico, destaca-se como fator determinante no ordenamento territorial e, em especial, da área urbana, onde a paisagem tem-se reconfigurado em razão da expansão da infraestrutura turística, que é elemento de destaque na prática do turismo, por favorecer o seu desenvolvimento.

Diante do exposto, como subsídio ao planejamento e manutenção da atividade turística, é fundamental realizar o cotejamento da distribuição espacial da infraestrutura turística com os atrativos oferecidos, comparação importante para o delineamento de ações que levem à antecipação de possíveis problemas ou que potencializem benefícios.

O presente trabalho tem como objetivo analisar e avaliar a distribuição da infraestrutura turística no polígono tombado de Pirenópolis, comparando-a com a localização dos atrativos turísticos no intuito de compreender sua contribuição para o desenvolvimento do turismo. 
Figura 1 - Mapa de localização de Pirenópolis, destacando o eixo Goiânia-Brasília²

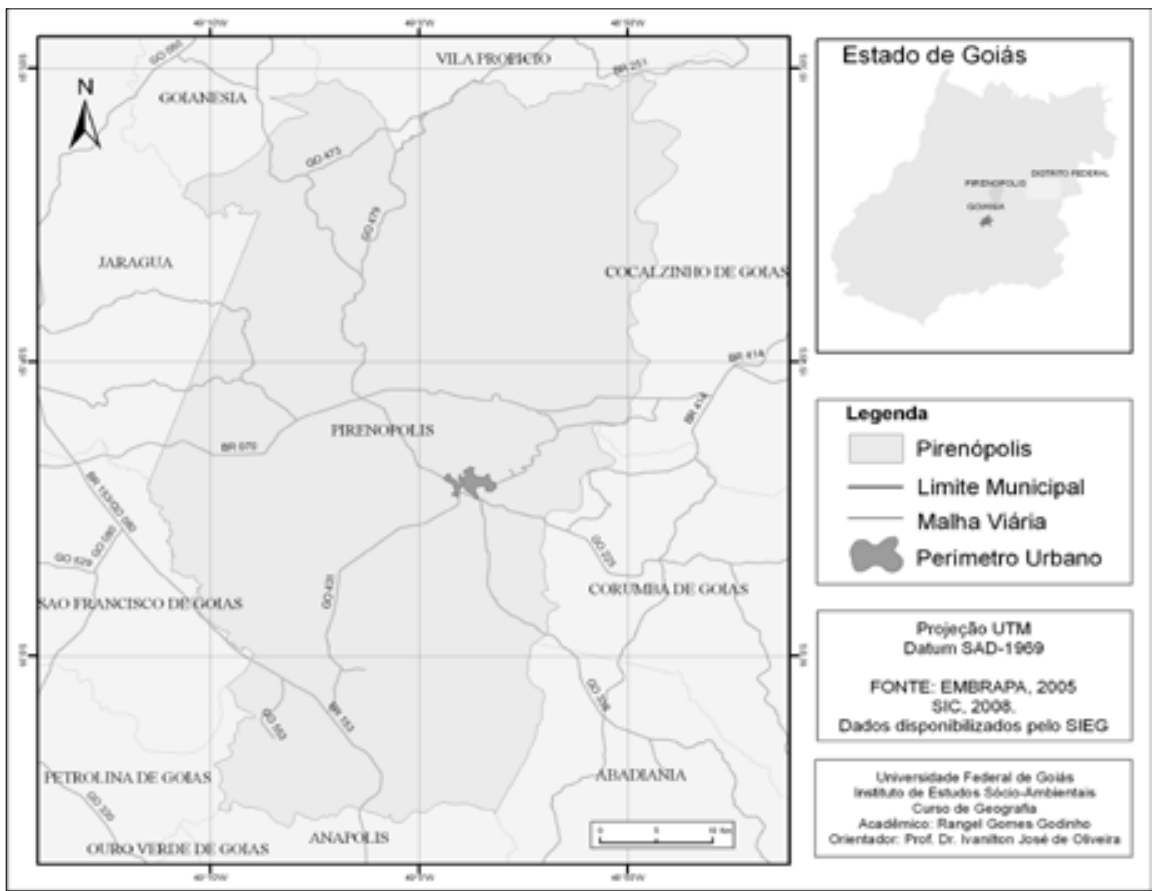

A realização deste trabalho envolveu, previamente, algumas etapas metodológicas. Inicialmente, foi feito um levantamento bibliográfico sobre a temática do turismo, com enfoque especial sobre o turismo em Pirenópolis. Concomitantemente, realizou-se o levantamento de bases cartográficas abrangendo os limites municipal e urbano. Na escala municipal, foram encontradas diversas bases em formato shape-files, disponibilizadas no portal eletrônico do Sistema de Informações Estatísticas e Geográficas (Sieg) da Secretaria de Planejamento e Desenvolvimento do estado de Goiás (Seplan/GO). Esses arquivos subsidiaram a confecção de mapas temáticos, trabalhados em ambiente de sistema de informação geográfica (SIG), utilizando-se os softwares Spring 5.0 e ArcGIS 9.2. Em relação à área urbana, o escritório de Pirenópolis do Instituto Nacional do Patrimônio Histórico e Artístico Nacional (Iphan) disponibilizou um arquivo com o mapeamento do Centro Histórico tombado na cidade. Em formato DWG, esse arquivo foi processado usando o software AutoCAD, 
depois foi exportado no formato DXF para ser trabalhado no Spring 5.0, o que possibilitou o mapeamento dos atrativos turísticos urbanos e dos diversos equipamentos turísticos considerados no trabalho. Na busca da existência de dados sobre a infraestrutura turística de Pirenópolis, também foram realizadas consultas a outros órgãos públicos como a Agência Goiana de Turismo (Agetur), a Secretária Municipal de Turismo de Pirenópolis e a Secretária de Planejamento e Desenvolvimento do estado de Goiás (Seplan).

Para a identificação e registro da infraestrutura turística e dos atrativos turísticos da área urbana, foram realizados diversos levantamentos de campo quando, então, foram percorridas todas as quadras do sítio tombado pelo Iphan. Esse inventário embasou a construção dos mapas dos atrativos turísticos e da infraestrutura turística com o fito de realizar o estudo e, assim, subsidiar as análises e discussões dos resultados.

Por fim, foram feitas algumas considerações que pudessem contribuir com a compreensão da produção do espaço geográfico pirenopolino, bem como apontar elementos relacionados à necessidade de espacialização de dados para a realização de um planejamento mais coerente com a realidade.

\section{0 fenômeno turístico e a apropriação do espaço pirenopolino}

Como prática social e atividade econômica, o turismo só passou a ser explorado em Pirenópolis após a melhoria das condições de acesso como fator indispensável para o fornecimento de minerais (quartzito) para a construção de Brasília na década de 1950. Conforme afirma Batista (2003), isso favoreceu o trânsito de pessoas e mercadorias, assim como a chegada de visitantes de outras regiões do país, como compradores de rochas, políticos e viajantes hippies; estes últimos, ao se estabelecerem no município de Pirenópolis, dedicaram-se ao artesanato em prata e posteriormente, em suas viagens para a venda de seus produtos, contribuíram para a divulgação da cidade, favorecendo o uso do espaço pirenopolino para a exploração turística. É importante destacar que a qualidade dos espaços de deslocamento pode incentivar ou inibir fluxos de viajantes.

Curado mostra que o lançamento de Pirenópolis no mercado consumidor turístico foi prematuro. Segundo a autora, o fluxo de turistas para Pirenópolis se deu sem que houvesse melhorias e incrementos em sua 
infraestrutura, ao mesmo tempo em que seu patrimônio não foi resguardado com políticas públicas, o que possibilitou depredações por parte dos turistas. A esse respeito, afirma Curado (1980, p. 156) que,

sem condições e mesmo sem interesse em planejá-lo, incentivá-lo, bem como de preservar os seus valores, corre o risco de perder a demanda turística ou ver extinguirem-se os seus atrativos ou, então, ambos a um só tempo.

Entretanto, Batista (2003) explica que o turismo em Pirenópolis intensificou-se a partir de 2000 em virtude do marketing efetuado pelo governo do estado de Goiás, durante o mandato de Marconi Perillo (19982006). Concomitantemente ao marketing turístico, outros programas governamentais foram implantados em Pirenópolis. Conforme mostra Drago (2003), esses programas serviram para aumentar os investimentos em infraestrutura de hospedagem e alimentação, assim como ampliar o número de estabelecimentos que dispõem de belezas naturais, disponibilizados para uso do turista.

Contudo, a mesma autora afirma que "este processo se deu e, ainda hoje, ocorre de forma desordenada, aleatória e com diversos empreendimentos cujos proprietários não apresentam vínculo com o município" (Drago, 2003, p. 122), o que implica em problemas de preservação cultural e dos recursos naturais.

O conjunto arquitetônico, urbanístico e paisagístico tombado em Pirenópolis originou-se de um acampamento de garimpeiros, e sua estrutura já havia se consolidado em 1750. Atualmente a prática do turismo cultural em Pirenópolis ocorre na área urbana por meio da apropriação dos recursos do patrimônio histórico-arquitetônico (dez atrativos) e da Festa do Divino Espírito Santo (Cavalhadas). O patrimônio histórico-arquitetônico da cidade foi tombado em 1989 pelo Instituto do Patrimônio Histórico e Artístico Nacional - Iphan, ${ }^{3}$ numa área que forma um polígono de 17 hectares como mostra a Figura 2. O patrimônio tombado é composto de igrejas, casarões, teatro, cinema, entre outros edifícios do período colonial.

Na área urbana, além do patrimônio histórico-arquitetônico, a oferta turística é composta também pelos espaços de banho e lazer localizados na orla do Rio das Almas, que corta o Centro Histórico e que são frequentados por turistas e moradores. Diante do uso turístico dessas áreas que compõem o atrativo natural urbano da cidade, de acordo com a 
Assessoria de Comunicação do Iphan, este órgão, em conjunto com o Ministério do Turismo, vai executar um projeto de revitalização da orla do Rio das Almas, denominado Beira Rio, para cuja execução estão previstos investimentos em torno de 6 milhões e 825 mil reais em obras.

Fora do ambiente urbano, o grande interesse turístico em Pirenópolis são os atrativos ligados ao meio físico, como cachoeiras, corredeiras e mirantes, além da vegetação preservada em propriedades rurais e unidades de conservação. Segundo dados da Secretaria Municipal de Turismo de Pirenópolis (2009), trinta e quatro atrativos dessa natureza são registrados nos limites do município. De acordo com Oliveira (2002), entre os municípios goianos, Pirenópolis é aquele que apresenta o maior número de unidades de conservação (UC), num total de sete: Parque Estadual dos Pireneus e Área de Preservação Ambiental da Serra dos Pireneus, além

Figura 2 - Área tombada como Patrimônio Histórico-Arquitetônico de Pirenópolis (GO)

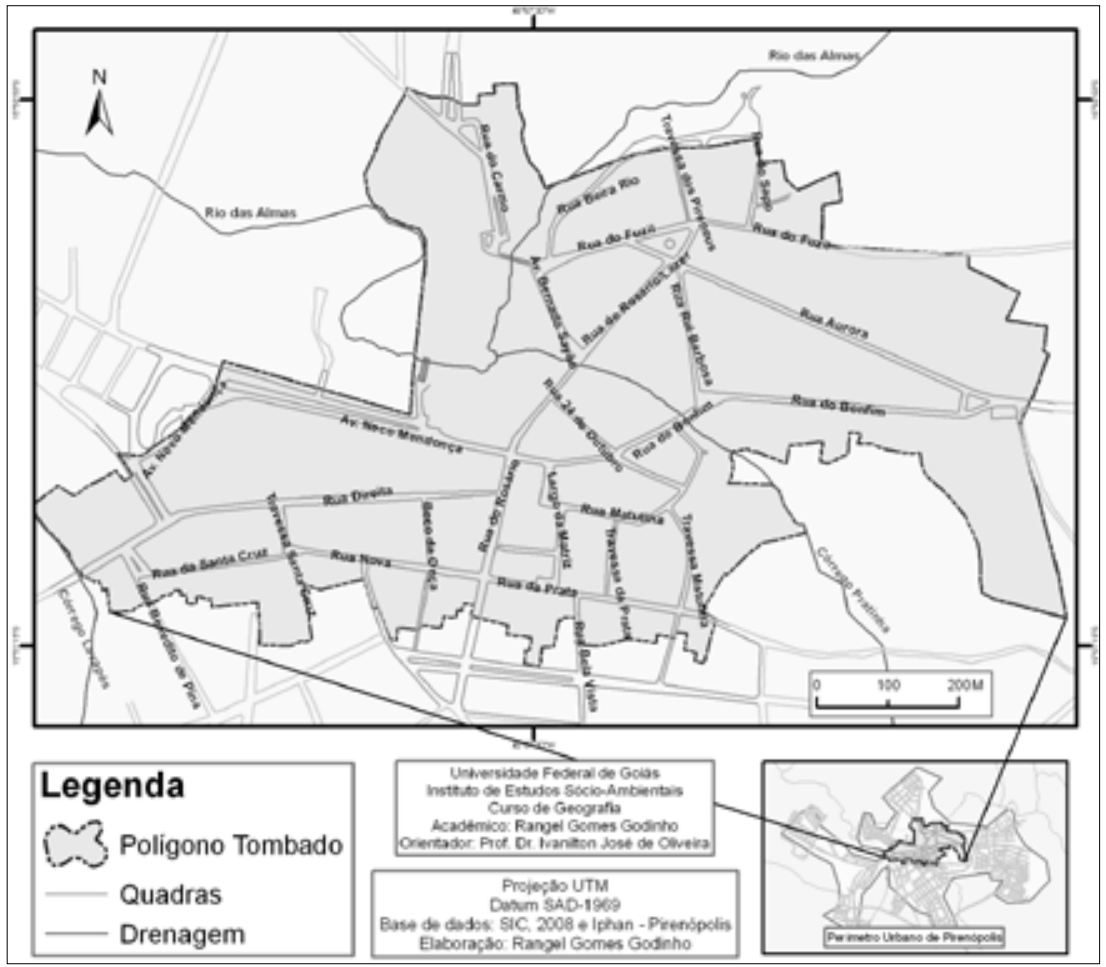


de cinco Reservas Particulares do Patrimônio Nacional (RPPN). Quanto ao uso turístico das unidades de conservação, Luchiari (2007) afirma que o patrimônio natural que deve ser preservado é apropriado pelo turismo e insere-se na lógica do capital e da especulação imobiliária, tornando-se atrativo para a expansão de empreendimentos turísticos. Nesse contexto, os atrativos devem ser tomados, no entendimento de Melgar (2001, p. 70), como um "conjunto de componentes localizados numa mesma região geográfica, em que no seu conjunto comportam um produto com autonomia suficiente para motivar o traslado de um grupo de pessoas".

\section{Distribuição geográfica dos atrativos culturais e infraestrutura turística}

O incremento e espacialização de infraestruturas voltadas para o turismo devem cooperar para o desenvolvimento dessa atividade, com o objetivo de atender a demanda turística em conformidade com a realidade local, o que exige um adequado planejamento do turismo de modo a estar sempre atento à produção do espaço pirenopolino.

A infraestrutura turística revela-se também como uma importante marca deixada pelo turismo na paisagem, pois sua forma pode vir a descaracterizar completamente o local. A paisagem aqui é entendida no sentido dado a ela por Santos (1997, p. 1), que a define como

um conjunto de objetos geográficos distribuídos sobre um território, sua configuração geográfica ou sua configuração espacial e a maneira como esses objetos se dão aos nossos olhos, na sua continuidade visível, isto é, a paisagem.

Barros (1998, p. 66) mostra que a difusão da infraestrutura acontece com o tempo, sendo este "o tempo da acumulação de efeitos e artefatos nas paisagens, ou tempo-histórico cumulativo", ocorrendo desta maneira a dinâmica histórico-geográfica das paisagens.

Portanto, a distribuição geográfica da infraestrutura turística permite também uma análise e avaliação da produção do espaço turístico, uma vez que o turismo impulsiona e exige objetos específicos - no caso a infraestrutura -, que é a materialização na paisagem do desenvolvimento da atividade.

Procurando compreender as transformações na paisagem e no espaço pirenopolino a partir da distribuição da infraestrutura e sua relação com os atrativos, a cartografia se destaca como elemento de suma impor- 
tância. O conjunto de conhecimentos voltados para a construção, manuseio e interpretação de mapas tem muito a contribuir para o raciocínio espacial - que se aplica, certamente, também ao espaço turístico. Oliveira (2005) e Menezes e Fernandes (2003) concordam em que a cartografia tem uma grande contribuição a dar no planejamento do turismo, pois os mapas podem (e devem) ser utilizados nas etapas de diagnóstico, implementação e avaliação de determinada atividade turística.

A cartografia associada ao geoprocessamento, usada na elaboração de mapas turísticos ou sobre o turismo, revela-se de grande importância em razão da possibilidade de cruzamento de mapas temáticos básicos a partir de sistemas de informações geográficas (SIG), favorecendo a análise e a avaliação da potencialidade turística de determinado espaço geográfico e servindo, portanto, de suporte para o planejamento de atividades turísticas (Oliveira, 2005; Carneiro et al., 2005; Menezes \& Fernandes, 2003).

Segundo o Iphan (2009), o conjunto arquitetônico, urbanístico e paisagístico tombado em Pirenópolis não sofreu alterações significativas até os dias atuais, ou seja, as características do período colonial estão fortemente expressas nos edifícios, casarões, praças e ruas, entre outros elementos espaciais. Na Figura 3 é possível observar que os atrativos culturais se concentram, em sua maioria, em duas áreas: (1) próximos ao Rio das Almas, na Rua do Carmo e Av. Bernado Sayão (este é o caso da Igreja Nossa Senhora do Carmo, da Ponte do Carmo e da Casa de Câmara e Cadeia); e (2) nas proximidades da Rua do Rosário e da Rua Direita (Igreja Nossa Senhora do Rosário, Cine Pireneus, Theatro Pirenópolis e Museu das Cavalhadas).

Na Rua Nova encontra-se o Museu da Família Pompeu. Já espacialmente mais dispersos estão a Igreja Nosso Senhor do Bonfim (Rua do Bonfim) e a Ponte Pêncil Dona Benta (perto da Av. Neco Mendonça).

Quanto à infraestrutura turística, foram consideradas as seguintes tipologias de infraestrutura: alimentícia, hospedagem, serviços turísticos, sinalização turística e lojas de artesanato, que foram sistematicamente identificadas e registradas a partir de diversos trabalhos de campo realizados na cidade de Pirenópolis, percorrendo os pesquisadores cada uma das ruas e vielas que compõem a área do polígono tombado pelo Iphan.

A infraestrutura alimentícia considerada neste trabalho subdivide-se em lanchonetes, restaurantes, sorveterias e bares. Embora alguns es- 
Figura 3 - Espacialização dos atrativos culturais da cidade de Pirenópolis

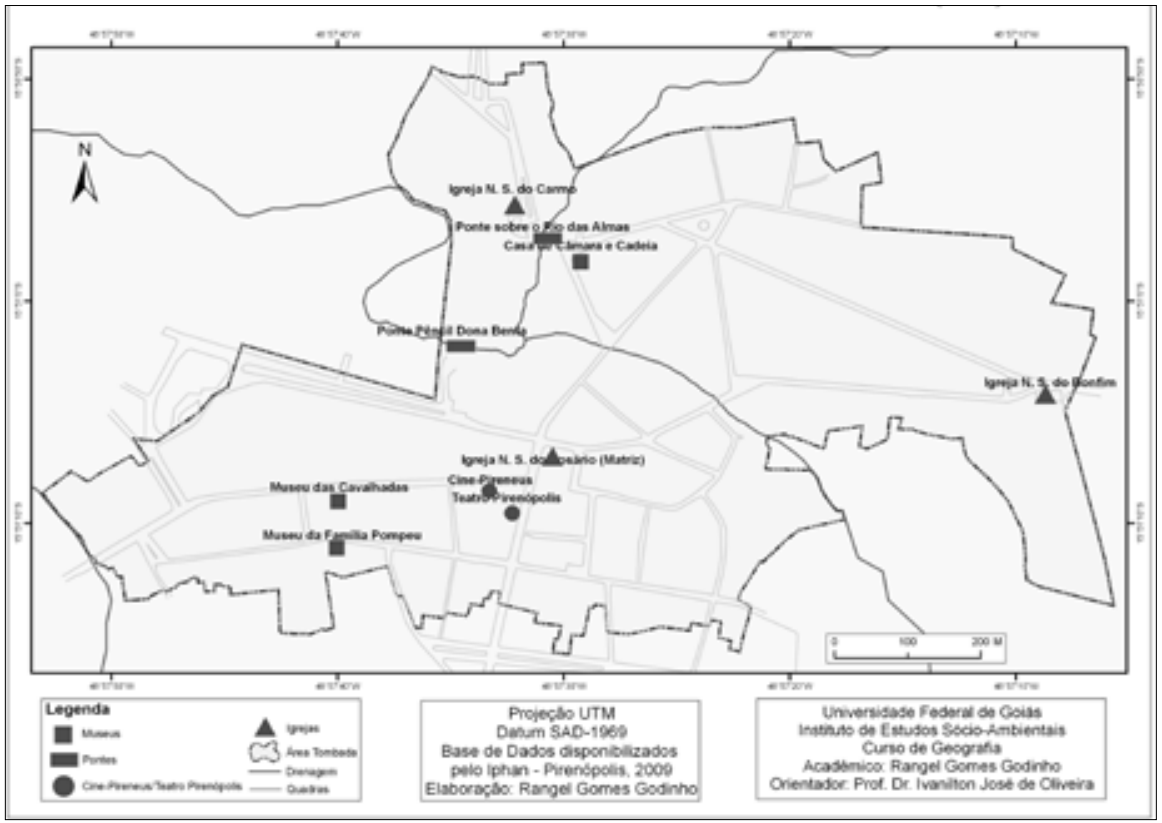

tabelecimentos acumulem mais de uma função, aquela considerada de maior destaque prevaleceu na classificação tipológica.

A distribuição espacial da infraestrutura alimentícia está expressa na Figura 4. Por meio dela, pode-se perceber que a localização de grande parte dos estabelecimentos não está relacionada com a localização dos atrativos culturais, como é o caso dos bares presentes na Rua do Lazer, onde há concentração deste tipo de estabelecimentos, que geralmente só começam a funcionar a partir do fim da tarde. Esses bares privilegiam o atendimento ao turista, uma vez que os valores das bebidas e alimentos são superiores aos encontrados em outros estabelecimentos da cidade. $\mathrm{O}$ valor do empadão goiano permite visualizar a diferença espacial dos preços, pois na Rua do Lazer é comercializado a 15 reais, enquanto na Rua Direita custa cinco (valores constatados no trabalho de campo).

$\mathrm{O}$ valor dos produtos comercializados está diretamente relacionado ao perfil do turista que frequenta Pirenópolis. De acordo com os dados da Agência Goiana de Turismo coletados em julho de 2002, 42,11\% dos 
turistas são de Brasília, enquanto 23,06\% provêm de Goiânia. Quanto à renda pessoal média, 27,57\% dos turistas entrevistados recebem entre um e dois mil reais, e $15,29 \%$ possuem renda entre dois e quatro mil reais. No que se refere à profissão, 29,32\% dos visitantes são funcionários públicos e $26,57 \%$ possuem emprego privado.

A leitura da Figura 4 permite observar que, na maioria dos casos, as lanchonetes e restaurantes estão locaizados próximo dos atrativos culturais, o que pode ser evidenciado na Rua do Carmo e Rua Nova, assim como nas proximidades das ruas Direita e do Rosário. Por sua vez, os outros estabelecimentos da infraestrutura alimentícia - bares e sorveterias - apresentam localização dispersa, no sentido da Rua do Bonfim e Rua Aurora.

As lojas de artesanato, que aqui estão subdivididas em "artesanato de prataria" e "artesanato em geral", são estabelecimentos marcantes na paisagem urbana pirenopolina. Como pode ser observado na Figura 5, elas se concentram em determinados espaços, como a Rua do Rosário (entre a Av. Bernardo Sayão e Rua do Bonfim) e a Rua Ruy Barbosa. Nes-

Figura 4 - Distribuição da infraestrutura de alimentação e dos atrativos culturais da cidade de Pirenópolis em 2009

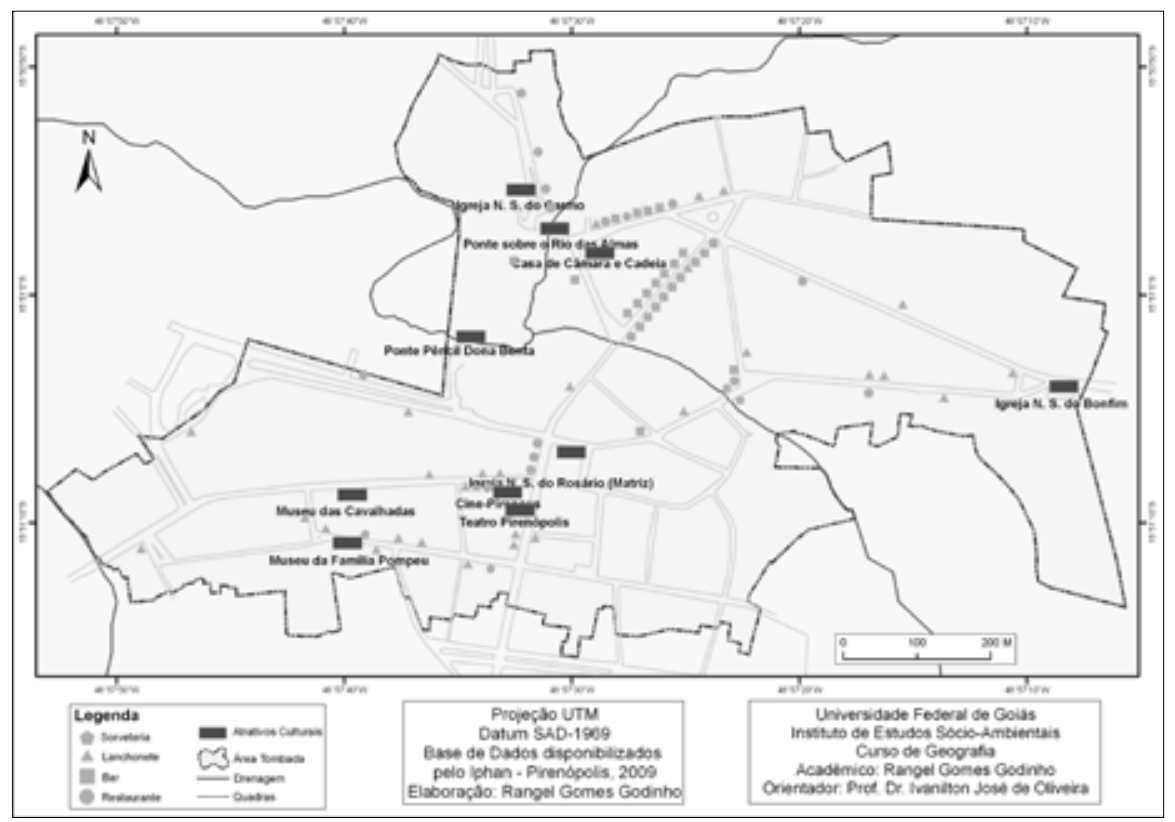


ses locais, as residências cederam a quase totalidade do espaço para lojas comerciais. São, hoje, uma referência na oferta turística de souvenirs, que em sua maioria lembram aspectos da cultura local: miniaturas de igrejas e caricaturas das cavalhadas, além de elementos naturais do município, como pequenas esculturas em rochas quartzíticas. Quanto à espacialização da infraestrutura comercial de artesanato, ela não guarda relação geográfica com a distribuição espacial dos atrativos culturais.

$\mathrm{Na}$ pesquisa de campo constatou-se a presença de uma tipologia composta de três modalidades de hospedagem: pousadas/hotéis, suítes e casas para temporada, com forte predomínio das pousadas.

Como mostra a Figura 6, a infraestrutura de hospedagem encontra-se bastante dispersa em toda a área tombada, não possuindo relação direta com os atrativos culturais. Observa-se uma concentração do número de pousadas/hotéis nas ruas que dão acesso aos atrativos naturais (Rua do Bonfim e Rua Aurora).

Figura 5 - Distribuição das lojas de artesanato no tocante à proximidade dos atrativos culturais da cidade de Pirenópolis, em 2009

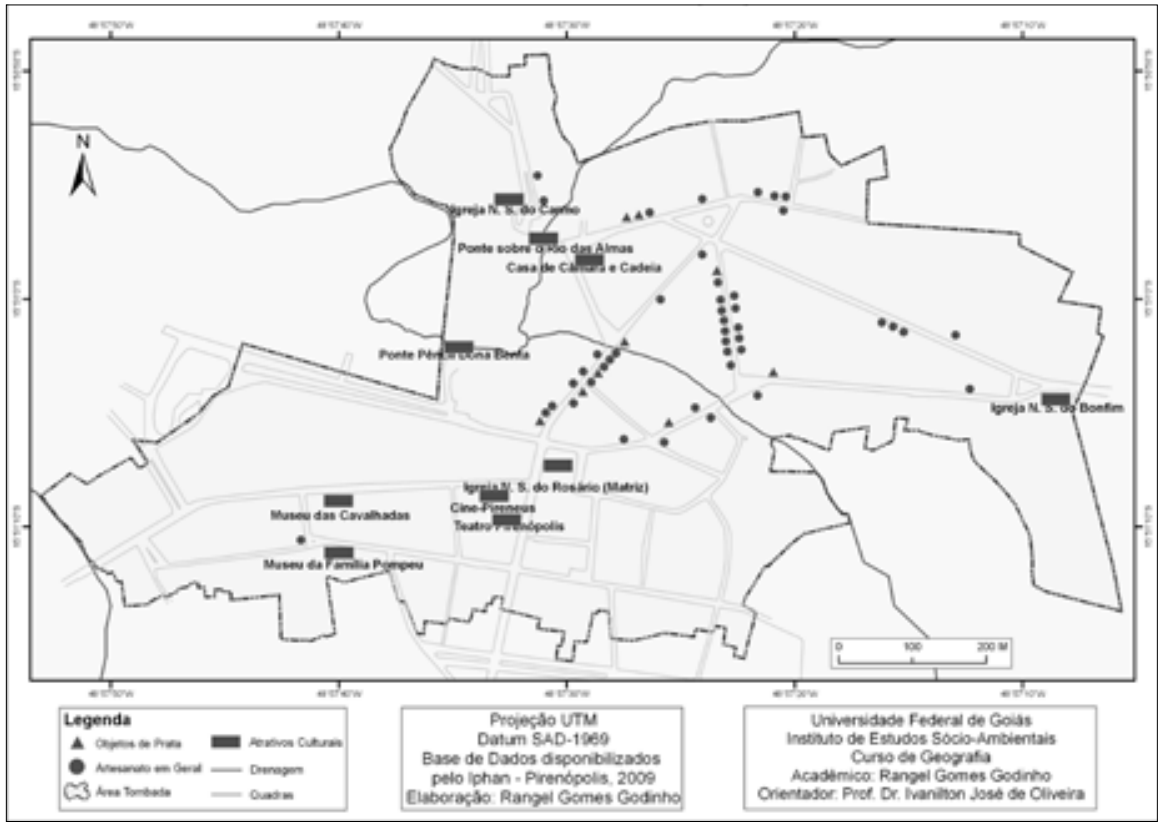


Figura 6 - Distribuição da infraestrutura de hospedagem em relação aos atrativos culturais da cidade de Pirenópolis, em 2009

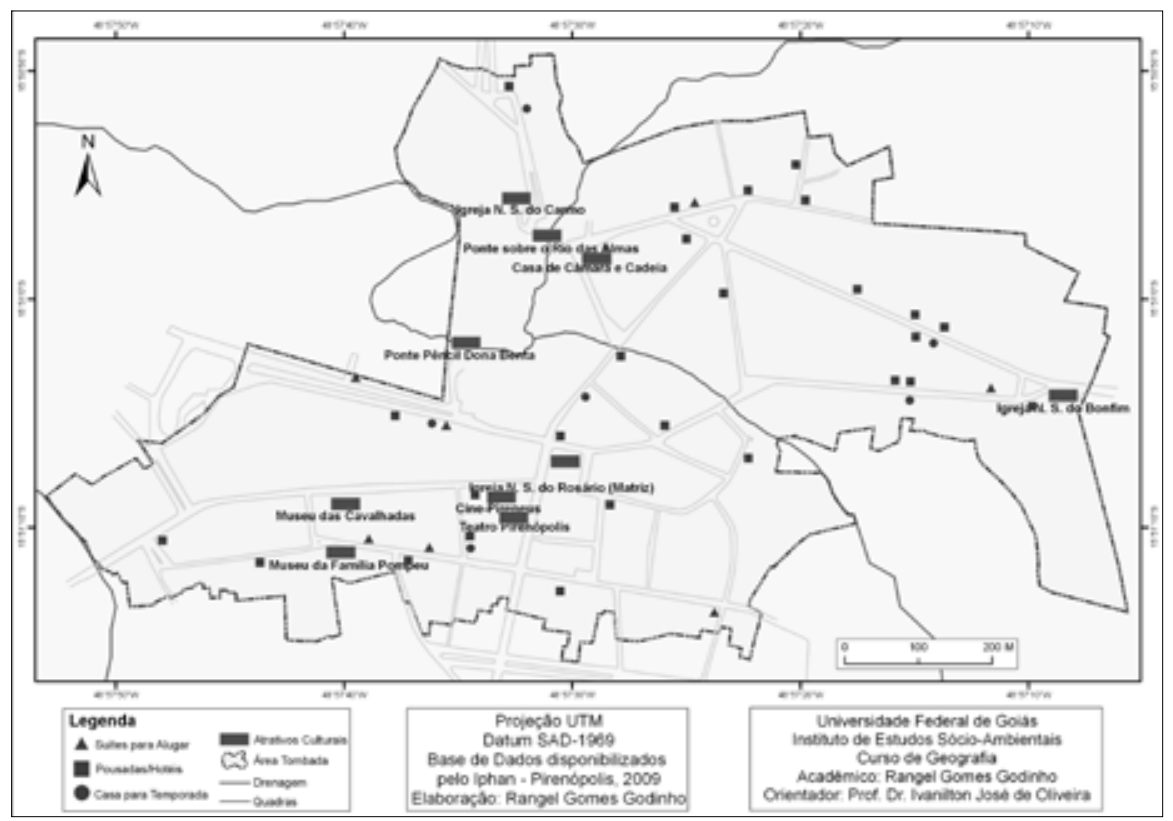

Quanto aos serviços destinados ao atendimento e orientação ao turista, constata-se que na área tombada há quatro agências de turismo e um Centro de Atendimento ao Turista (CAT). Existe um total de oito placas indicativas de sinalização para os turistas. Entre essas, duas contêm a mesma informação, conforme apresentado no Quadro 1. Observa-se que a sinalização não faz referência aos diversos atrativos turísticos do município, em especial os culturais. Sua distribuição geográfica também não permite ao turista identificar a área que foi tombada, assim como não favorece o deslocamento dos turistas e a interpretação do patrimônio cultural.

De modo geral, conclui-se que a distribuição geográfica da infraestrutura turística na área tombada obedece a padrões que seguem as diversas tipologias listadas, mas que não favorecem a visitação e a fruição do patrimônio cultural, pois se distribuem aleatoriamente por todo o polígono.

No caso da infraestrutura de hospedagem e de alimentação em especial, percebe-se que a localização dos estabelecimentos tende a favo- 
Quadro 1 - Conteúdo da sinalização turística da área tombada de Pirenópolis - 2009

\begin{tabular}{l|l|l}
\hline \multicolumn{2}{c}{ Sinalização turística } \\
\hline $\begin{array}{l}\text { Igreja Nossa } \\
\text { Senhora do Carmo }\end{array}$ & $\begin{array}{l}\text { Ponte Nova/Igreja N. S. } \\
\text { do Carmo/Igreja N. S. do } \\
\text { Bonfim }\end{array}$ & $\begin{array}{l}\text { Igreja Nosso Senhor do } \\
\text { Bonfim/Igreja Nossa } \\
\text { Senhora do Carmo }\end{array}$ \\
\hline $\begin{array}{l}\text { Igreja N.S. do } \\
\text { Carmo/Iphan }\end{array}$ & $\begin{array}{l}\text { Igreja Nossa Senhora do } \\
\text { Carmo }\end{array}$ & $\begin{array}{l}\text { Santuário Vaga Fogo/ } \\
\text { Santuário Flor das Águas }\end{array}$ \\
\hline $\begin{array}{l}\text { Piretur/CAT/Igreja } \\
\text { Nosso Senhor do } \\
\text { Bonfim }\end{array}$ & $\begin{array}{l}\text { Igreja Nossa Senhora } \\
\text { do Carmo/Santuários } \\
\text { Ecológicos/Cachoeiras }\end{array}$ & \\
\hline
\end{tabular}

Fonte: Inventário elaborado a partir da identificação e registro da infraestrutura turística e atrativos turísticos, por meio de trabalho de campo realizado entre os dias 20 de julho e $1^{\circ}$ de agosto de 2009 na área tombada como Patrimônio HistóricoArquitetônico de Pirenópolis (GO).

Figura 7 - Distribuição dos serviços de atendimento e sinalização turística em relação aos atrativos culturais da cidade de Pirenópolis, em 2009

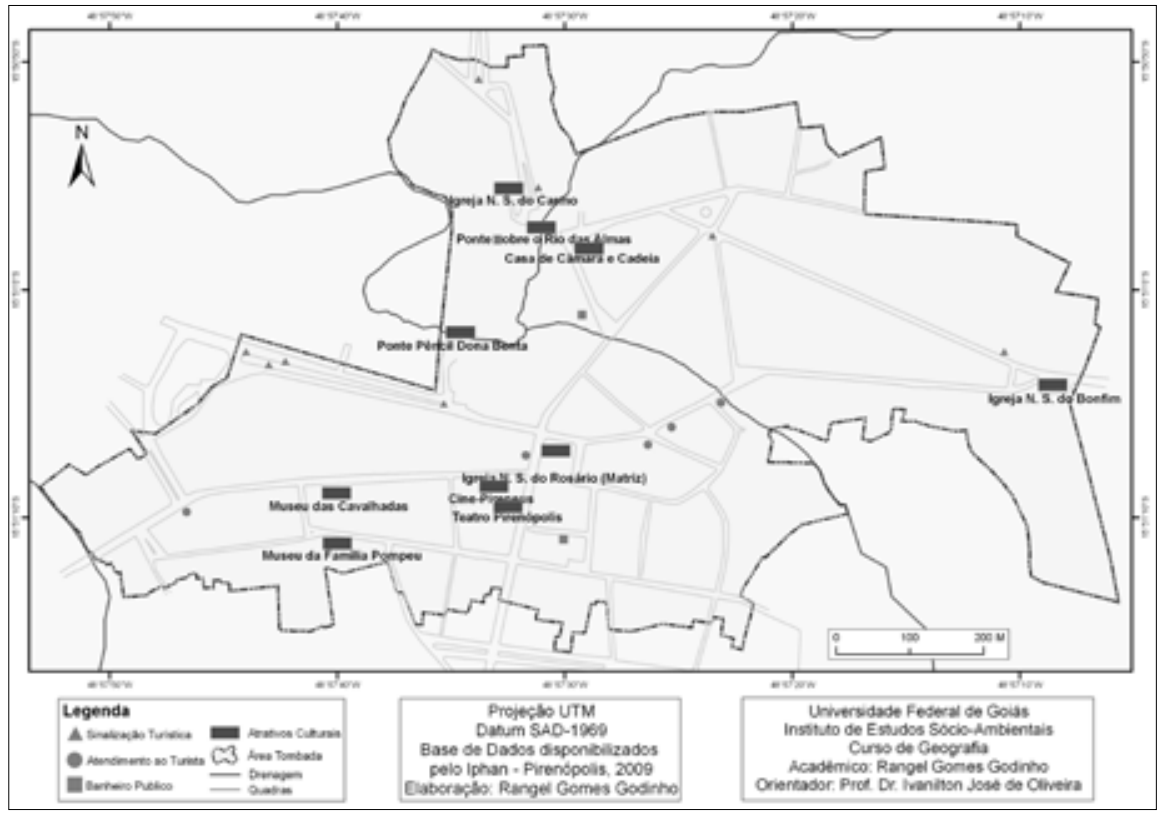


recer mais o uso turístico do patrimônio natural que o cultural, já que há uma clara concentração espacial na parte nordeste do sítio urbano, justamente a área de saída para as cachoeiras e para o Parque Estadual dos Pireneus.

\section{Considerações finais}

A partir da análise e avaliação da distribuição da infraestrutura turística da área tombada como patrimônio histórico-arquitetônico, constata-se a necessidade de investimento em políticas que incentivem a criação de infraestruturas que atendam diretamente os atrativos culturais, com o fito de permitir que os turistas consigam identificá-los e reconhecê-los como elementos importantes da oferta turística. Nesse sentido, há necessidade de criação de mapas e roteiros turísticos urbanos que destaquem o patrimônio cultural e orientem o deslocamento dos turistas, favorecendo o processo de interpretação do legado histórico-arquitetônico, levando ao estabelecimento de relações afetivas com a cultura local e fazendo com que o espaço seja mais que um objeto de consumo.

A cartografia turística, além de ser um importante subsídio à análise e avaliação da atividade turística, pode elaborar informações espaciais que deverão subsidiar estudos mais aprofundados referentes ao desenvolvimento dessa atividade e sua sustentabilidade econômica, ambiental e social. Portanto, serve como instrumento de gestão que apoie políticas públicas voltadas ao turismo, racionalizando a atividade.

Outro elemento importante que não deve ser negligenciado é a sinalização turística, que necessita de ser alterada para contribuir com a localização dos diversos atrativos urbanos, bem como ser melhor distribuída espacialmente dentro do polígono tombado, pois sua adequada posição geográfica é um meio de apresentar aos turistas os atrativos culturais e racionalizar seu deslocamento.

Por fim, constata-se que a produção do espaço pirenopolino é direcionada pelo turismo e que as transformações na paisagem são um importante elemento indicativo da dinâmica socioespacial da cidade de Pirenópolis. Esta dinâmica pode ser apreendida pela análise e avaliação da espacialização da infraestrutura turística, revelando a lógica do ordenamento territorial que, conforme foi evidenciado no presente trabalho, não se orienta em razão dos aspectos culturais. 


\section{Notas}

1 Esse artigo apresenta resultados obtidos no desenvolvimento do projeto "Análise de paisagens e cartografia turística aplicadas à fruição do patrimônio ambiental do município de Pirenópolis (GO)”, que conta com financiamento do CNPq e Fapeg.

2 Todos os mapas apresentados no presente trabalho foram elaborados pelos próprios autores.

3 Livro do Tombo: Histórico, volume 2; inscrição 530; processo n. 1181-T-41.

\section{Referências}

BARROS, Nilson Cortez de. Manual de geografia do turismo: meio ambiente, cultura e paisagem. Recife: Ed. da UFPE, 1998. 108p.

BATISTA, Ondimar. Pirenópolis: uma paisagem ora vivida, ora contemplada. In: ALMEIDA, Maria Geralda de (Org.). Paradigmas do turismo. Goiânia: Alternativa, 2003. p 113-120.

BRASIL. Instituto do Patrimônio Histórico e Artístico Nacional (Iphan). Disponível em: www.iphan.gov.br. Acesso em: ago. 2009.

CARNEIRO, A. M. C.; MOURA: Oliveira; Ramos; Santana . A representação em realidade virtual da Estrada Real: novos caminhos na Cartografia destinada ao Turismo. In: XXII Congresso Brasileiro de Cartografia, 2005, Macaé, RJ. Anais do XXII Congresso Brasileiro de Cartografia, 2005. p. 1-5.

CRUZ, Rita de Cássia Ariza da. O turismo no espaço, o espaço do turismo: reflexões acerca da participação do turismo na produção do espaço urbano brasileiro. RA'E GA - O espaço geográfico em análise, n. 2, p. 31-41, Curitiba, 1998.

CURADO, Glória Grace. Pirenópolis: uma cidade para o turismo. Goiânia: Oriente, 1980.

DRAGO, Theandra Fernandes. Desenvolvimento turístico municipal: o caso de Pirenópolis, Goiás. In: ALMEIDA, Maria Geralda de (Org.). Paradigmas do turismo. Goiânia: Alternativa, 2003. p. 121-122.

GOIÁS. Agência Goiana de Turismo. Goiás - Brasil: turismo em dados, caminho do ouro. Disponível em: www.goiasturismo.com.br. Acesso em: jun. 2009.

LUCHIARI, Maria Tereza D. Paes. Turismo e patrimônio natural no uso do território. In:___.; BRUHNS, Heloisa Turini e SERRANO, Célia (Orgs.). Patrimônio, natureza e cultura. Campinas (SP): Papiros, 2007. p. 25-45.

MELGAR, Ernesto. Fundamentos de planejamento e marketing em turismo. São Paulo: Contexto, 2001. 117 p.

MENEZES, P. M. L. de e FERNANDES, M. do C. Cartografia turística: novos conceitos e antigas concepções. In: XXI CONGRESSO BRASILEIRO DE CARTOGRAFIA, 21, 2003, Belo Horizonte. Anais... Belo Horizonte: UFMG, 2003. p. 1-8.

OLIVEIRA, Ivanilton José de. A cartografia aplicada ao planejamento do turismo. Boletim Goiano de Geografia, v. 25, n. 1-2, p. 29-46, Goiânia, 2005. 
OLIVEIRA, Sandra de Fátima. Unidades de conservação: contexto histórico e a realidade do estado de Goiás. In: ALMEIDA, Maria Geralda de (Org.). Abordagens geográficas de Goiás: o natural e o social na contemporaneidade. Goiânia: IESA, 2002. p. 223-243.

PIRENÓPOLIS. Secretária Municipal de Turismo de Pirenópolis. Pirenópolis (GO): 2009. (No prelo).

RODRIGUES, Adyr Balastreri. Turismo e espaço: rumo a um conhecimento transdisciplinar. São Paulo: Hucitec, 1999.

SANTOS, Milton. Espaço e método. São Paulo: Nobel, 1997. (Espaços).

Rangel Gomes Godinho - Mestrando em Geografia do Instituto de Estudos Sócio-Ambientais - Universidade Federal de Goiás.

Ivanilton José de Oliveira - Professor do Instituto de Estudos Sócio-Ambientais - Universidade Federal de Goiás.

Recebido para publicação em março de 2010 Aceito para publicação em maio de 2010 